\title{
Lower Handgrip Strength is Associated with Worse Quality of Life and More Fatigue and Disability in Long- term Colorectal Cancer Survivors
}

Maarten van Heinsbergen ( $\nabla$ mvheinsbergen@viecuri.nl)

VieCuri Medical Centre Venlo https://orcid.org/0000-0002-8092-6713

\section{Janssen-Heijnen}

VieCuri Medical Centre: VieCuri Medisch Centrum

JL Konsten

VieCuri Medical Centre: VieCuri Medisch Centrum

\section{ND Bouvy}

Maastricht University Hospital: Maastricht Universitair Medisch Centrum+

\section{MP Weijenberg}

Maastricht University Faculty of Health, Medicine and Life Sciences: Maastricht Universitair Medisch Centrum+

\section{MJL Bours}

Maastricht University Faculty of Health, Medicine and Life Sciences: Maastricht Universitair Medisch Centrum+

\section{Research Article}

Keywords: Colorectal Cancer Surgery, Health-related Quality of Life, Postoperative complications, Morbidity, Handgrip strength

Posted Date: July 6th, 2021

DOl: https://doi.org/10.21203/rs.3.rs-339312/v1

License: (1) This work is licensed under a Creative Commons Attribution 4.0 International License. Read Full License 


\section{Abstract}

Colorectal cancer (CRC) treatment negatively affects anthropometric measures, which in turn can result, either directly or indirectly, in fatigue and a lower health-related quality of life (HRQoL). Since anthropometric measures are modifiable, we examined which of these are associated with HRQoL, fatigue, and disability in long-term CRC survivors.

In this cross-sectional study, body mass index (BMI), waist circumference, waist-to-hip ratio, body fat percentage, handgrip strength (HGS) and mid-upper arm muscle area of 155 stage I-III CRC survivors at 2-10 years after treatment were assessed during home visits (response rate 42\%). HRQoL was measured by the EORTC QLQ-C30, fatigue by the Checklist Individual Strength (CIS), and disability by the World Health Organization Disability Assessment Schedule II (WHODAS-II). Associations between anthropometric measures and HRQoL, fatigue and disability were analyzed by confounder-adjusted linear regression.

Mean time since $C R C$ diagnosis was 5.7 years $(S D=1.8)$, and mean age was 70.1 years $(S D=8.9)$. After adjustment for patient and treatment characteristics, only HGS was independently associated with HRQoL. Each increase in participants' HGS of $5 \mathrm{~kg}$ was significantly associated with an increase of 2.3 points $(95 \% \mathrm{Cl}=0.3$, $4.3)$ in global quality of life, 2.9 points $(95 \% \mathrm{Cl}=0.9,5.0)$ in physical functioning, 3.3 points $(95 \% \mathrm{Cl}=1.3,5.3)$ in social functioning, and a decrease of 5.9 points $(95 \% \mathrm{Cl}=-8.7,-3.0)$ in fatigue symptoms and 2.5 points $(95 \% \mathrm{Cl}$ $=-4.1,-0.9)$ in disability.

We conclude that HGS, as a measure of physical functioning in CRC survivors, was independently associated with HRQoL, fatigue and disability. Future prospective research should focus underlying and causal factors in the association between HGS and HRQoL after CRC treatment and on possible interventions to promote HRQoL outcomes through improving physical functioning.

\section{Introduction}

Worldwide, colorectal cancer (CRC) is the third most commonly diagnosed cancer in males (10\%) and the second in females $(9.2 \%)[1,2]$. While the incidence of CRC has been increasing, morbidity and mortality rates have been decreasing. The increasing incidence is likely to be caused by aging of the population, while advanced screening methods and improved treatments lead to a steady increase in the number of CRC survivors [1-4]. Increasing number of patients surviving CRC not only makes oncological outcome important but also health-related quality of life (HRQoL), which might be negatively influenced by long-lasting adverse effects of CRC treatment such as bowel dysfunction and a decrease in physical functioning [5]. In order to develop tailored interventions to improve quality of life in cancer survivors, it is essential to gather evidence about underlying modifiable factors contributing to a decreased HRQoL in CRC survivors.

Growing evidence derived from various observational studies consistently shows a positive association between physical activity on the one hand and HRQoL, reduced fatigue symptoms, increased survival rate and decreased treatment side effects on the other hand in CRC survivors [6-10]. Poor dietary habits, obesity and decreased physical activity are often present in patients who are diagnosed with CRC [11]. Physical function might be further decreased as a result of cancer treatment, that negatively affects anthropometric measures, such as muscle strength or body composition $[12,13]$. Therefore, CRC treatment can result either directly or indirectly via 
physical function and the effect on anthropometric measures, in fatigue and a lower quality of life for treated patients, in the years after the end of treatment [14-18].

As anthropometric measures are modifiable, it is important to identify which of these measures are associated with a better physical functioning and a better HRQoL in the years after the end of treatment. Current studies among CRC patients mainly focus on the association between certain anthropometric measures and patients' physical function instead of studying the direct relation with HRQoL [11, 19-24].

These prospective and cross-sectional studies have found that obesity in the period from 6 months until 10 years after CRC diagnosis was associated with a lower HRQoL in CRC survivors, in particular in patients with a lower level of physical functioning [11, 19-24]. Nevertheless, among CRC patients, associations between BMI and outcomes such as HRQoL and survival seem divergent since both a low and high BMI can be associated with worse HRQoL [7, 25-27].

Instead of BMI, other anthropometric measures, such as waist circumference, waist-to-hip ratio (WHR) and foursite skinfold measurement might be used for body fat and fat distribution [22, 28, 29]. These measures have been found to be associated with improved survival and HRQoL among patients with gastrointestinal cancer, with greater anthropometric measures predicting a poorer survival and HRQoL [27,30]. Previous studies have also shown that lower handgrip strength (HGS), as a measure of muscle weakness, is associated with a poor quality of life in frail elderly patients [31] and among lung and breast cancer patients [32-34].

This means that besides BMI, associations between other anthropometric measures and HRQoL after CRC treatment need to be studied in order to identify factors that can potentially be influenced before, during and after cancer treatment, such as supervised specific muscle training programs. Since studies investigating a direct association between anthropometric measures and patients' HRQoL in CRC survivors are scarce and often only include BMI as anthropometric measure, this study aims to examine the association between extensive anthropometric measures and HRQoL, fatigue, and disability in long-term CRC survivors.

\section{Study Design And Participants}

For this paper, data were used from the cross-sectional part of the Energy for life after ColoRectal cancer (EnCoRe) study, conducted in stage I-III CRC survivors who were 2-10 years post-diagnosis. Methods of the EnCoRe study, which consists of an ongoing prospective part and a cross-sectional part, have been described previously [35]. Eligible subjects, i.e. stage I-III CRC survivors diagnosed and treated between 2002 and 2010 at Maastricht University Medical Center+, the Netherlands, were preselected via the Netherlands Cancer Registry (NCR; managed by Comprehensive Cancer Centre the Netherlands) and eligible subjects were invited for participation by mail. Reasons for exclusion were death before the start of the study, stage IV disease, comorbidities obstructing successful participation such as Alzheimer disease or severe hearing disorders, and inability to understand the Dutch language (Fig. 1). Participant recruitment and study measurements took place between May 2012 and December 2013. The EnCoRe study had been approved by the Medical Ethics Committee of the Academic Hospital Maastricht and Maastricht University, the Netherlands. Written informed consent was obtained from all participants.

\section{Data Collection}




\section{Anthropometric measures}

An extensive anthropometric assessment was performed by trained personnel during study visits at participants' homes. Body weight and height were measured with a portable scale (electronic scale type 861, Seca LTD, Birmingham, UK) and tape measure, respectively, and used for the calculation of body mass index $\left(\mathrm{BMl}, \mathrm{kg} / \mathrm{m}^{2}\right)$ as a measure of body fatness. Body fat percentage was determined based on measurement of the thickness $(\mathrm{mm})$ of triceps, biceps, subscapular, and suprailiac skinfolds, using a skinfold caliper (Holtain LTD, Crymych, UK). Measurements were performed thrice per skinfold and the sum of the median thickness of the four skinfolds was used to calculate body fat percentage based on formulas provided by Durnin and Womersley [36]. In addition, several circumference measurements $(\mathrm{cm})$ were performed in duplicate using a circumeter (type 05335, Premed, Bilthoven, NL), including mid-upper arm, waist, and hip circumference. The mean values of the duplicate waist and hip circumference measurements were used to calculate the waist-to-hip ratio as a measure of body fat distribution. Mid-upper arm circumference was used in combination with the triceps skinfold to calculate the mid-upper arm muscle area $\left(\mathrm{cm}^{2}\right)$ as a measure of muscle mass, using the following formula: $1 / 4 \pi$ (mid-upper arm circumference - [triceps skinfold] $\pi)^{2}[37,38]$. Finally, maximum isometric handgrip strength (HGS) of the dominant hand was measured with a validated Jamar hydraulic dynamometer (Sammons Preston Rolyan, Chicago, USA) [39] as a measure of general muscle strength [40]. Participants performed two HGS measurements with sufficient rest in-between; the highest value was considered the maximum HGS $(\mathrm{kg})$.

\section{Health-related quality of life outcomes}

Cancer-specific HRQoL was measured with the European Organisation for Research and Treatment of Cancer Quality of Life Questionnaire-Core 30 (EORTC QLQ-C30, version 3.0), which is a reliable and valid measure for HRQoL in patients with cancer [41, 42]. For the subscales global health status/quality of life and physical, role, and social functioning, 100-point scores were calculated with higher scores indicating higher levels of quality of life or functioning [43]. Furthermore, disability was assessed by the 12-item version of the World Health Organization Disability Assessment

Schedule II (WHODAS II) [44, 45]. The WHODAS II has a good reliability and validity in different populations, including elderly individuals and breast cancer survivors [45-47]. A total disability score (100-point scale) was calculated, with a higher score indicating a higher level of disability [45]. In addition, fatigue was assessed through the Checklist Individual Strength (CIS), which was originally developed and validated in patients with chronic fatigue syndrome [48, 49], but has also been applied in cancer survivors [50]. Individual items from the $\mathrm{CIS}$ were summed to calculate a total score for fatigue (scale: 20-140), with higher scores indicating higher levels of fatigue.

\section{Other variables}

The Short QUestionnaire to ASsess Health-enhancing physical activity (SQUASH) was used to measure habitual activity level and adherence to national physical activity guideline (> $150 \mathrm{~min} /$ week of moderate-to-vigorous physical activity) $[35,51]$. Participants were also requested to wear a tri-axial accelerometer on the anterior upper leg for 7 consecutive days to determine intensity, frequency, and duration of daily activities like walking, standing, and lying, as well as to determine sedentary time [52]. To measure their total energy intake (kcal), participants were asked to fill out a seven-day dietary record to assess consumption of all foods and drinks over a 1-week period. Socio-demographic characteristics (gender, age, education level) and smoking status were self- 
reported [11]. Presence of comorbidities was assessed during the study visits at participants' homes [53]. Primary data on patient, tumour and treatment characteristics (cancer stage, age at diagnosis, chemotherapy/radiotherapy treatment, and tumour subsite) were derived from the Netherlands Cancer Registry.

\section{Statistical analysis}

Patient characteristics were summarized with descriptive statistics for the total study population and for men and women separately. Multivariable linear regression models were used to analyse associations of the body composition parameters of interest (BMI, waist circumference, waist-to-hip ratio, body fat percentage, maximum HGS, and mid-upper arm muscle area) with global QoL, with physical, role and social functioning, and with fatigue and disability as HRQoL outcomes. All regression analyses were adjusted for a predefined set of relevant confounders, which were selected based on our previously developed conceptual model for studying lifestyle factors and HRQoL in CRC survivors [35] and included age (years), gender, years since diagnosis, comorbidities (0/1/2 + comorbid conditions), chemotherapy treatment (yes/no), current smoking (yes/no), moderate-tovigorous physical activity $(\mathrm{h} / \mathrm{w})$, sedentary time $(\mathrm{h} / \mathrm{d})$, and total energy intake $(\mathrm{kcal} / \mathrm{d})$. Unadjusted and confounder-adjusted regression coefficients (B) with $95 \%$ confidence intervals $(95 \% \mathrm{Cl})$ reflecting associations between body composition parameters and HRQoL outcomes are presented. Values of $P<0.05$ were considered to indicate statistical significance. All statistical analyses were performed using IBM ${ }^{\circledR}$ SPSS $®$ Statistics, version 22.

\section{Results}

\section{Population characteristics}

A total of 373 eligible CRC survivors were invited to participate, of whom 155 were recruited (response rate $=$ $42 \%$; Fig. 1). Participants were on average 3.9 years younger, had more often been diagnosed with rectal cancer ( $42 \%$ vs. $36 \%$ ) and had more frequently received treatment with chemotherapy ( $52 \%$ vs. $43 \%$ ) and radiotherapy (39\% vs. $30 \%)$, than non-participants. No differences were observed in gender, years since diagnosis, and TNM stage. As shown in Table 1, a total of 96 male (62\%) and 59 female (38\%) CRC survivors were included, who were on average 70.1 years of age (standard deviation $[S D]=8.9)$ and 5.7 years since $C R C$ diagnosis $(S D=1.8)$. Of these, 80 survivors (53\%) had a previous diagnosis of colon cancer, $64(42 \%)$ rectum cancer and $7(5 \%)$ rectosigmoid cancer. Seventy-one (46\%) survivors were overweight, $44(29 \%)$ obese, and $38(25 \%)$ had normal weight; one participant was underweight. A total of $79(51 \%)$ survivors reported two or more comorbid conditions. 
Table 1

Anthropometric measures of body composition and other characteristics of the study population of colorectal cancer survivors.

\begin{tabular}{|c|c|c|c|}
\hline & $\begin{array}{l}\text { Total } \\
(N=155)\end{array}$ & $\begin{array}{l}\text { Men } \\
(N=96,62 \%)\end{array}$ & $\begin{array}{l}\text { Women } \\
(N=59,38 \%)\end{array}$ \\
\hline Anthropometric measures & Mean (SD) & Mean (SD) & Mean (SD) \\
\hline Body mass index $\left(\mathrm{kg} / \mathrm{m}^{2}\right)$ & $27.7(4.3)$ & $27.5(3.4)$ & $28.1(5.5)$ \\
\hline Waist circumference (cm) & $99.8(11.1)$ & $102.3(9.6)$ & $96.7(12.3)$ \\
\hline Waist-to-hip ratio & $0.98(0.08)$ & $1.02(0.07)$ & $0.91(0.07)$ \\
\hline Body fat (\%) & $34.9(6.4)$ & $31.6(4.7)$ & $40.5(4.9)$ \\
\hline Maximum handgrip strength $(\mathrm{kg})$ & $37.2(12.6)$ & $44.1(9.9)$ & $25.7(6.7)$ \\
\hline \multirow[t]{2}{*}{ Mid-upper arm muscle area $\left(\mathrm{cm}^{2}\right)$} & $470.0(116.1)$ & $511.4(104.2)$ & $401.7(102.1)$ \\
\hline & $N(\%)$ & $N(\%)$ & $N(\%)$ \\
\hline Underweight & $1(0.6)$ & $0(0.0)$ & $1(1.7)$ \\
\hline Normal weight & $38(24.7)$ & $21(21.9)$ & $17(29.3)$ \\
\hline Overweight & $71(46.1)$ & $54(56.3)$ & $17(29.3)$ \\
\hline Obese & $44(28.6)$ & $21(21.9)$ & $23(39.7)$ \\
\hline Lifestyle-related characteristics & Mean (SD) & Mean (SD) & Mean $(S D)$ \\
\hline Moderate-to-vigorous physical activity (h/w) & $12.9(14.9)$ & $15.9(17.6)$ & $8.0(6.2)$ \\
\hline Prolonged sedentary time $(\mathrm{h} / \mathrm{d})$ & $10.2(1.7)$ & $10.5(1.5)$ & $9.6(1.8)$ \\
\hline \multirow[t]{2}{*}{ Total energy intake (kcal/d) } & $1958(475)$ & $2176(418)$ & $1602(326)$ \\
\hline & $N(\%)$ & $N(\%)$ & $N(\%)$ \\
\hline Current smoking (yes) & $16(10.5)$ & $12(12.8)$ & $4(6.9)$ \\
\hline Adherence to physical activity standard (yes) & $75(50.0)$ & $56(60.2)$ & 19 (33.3) \\
\hline Sociodemographic characteristics & Mean (SD) & Mean (SD) & Mean (SD) \\
\hline \multirow[t]{2}{*}{ Age $(y)$} & $70.1(8.9)$ & $70.2(8.2)$ & $70.0(9.9)$ \\
\hline & $N(\%)$ & $N(\%)$ & $N(\%)$ \\
\hline Low education level & $37(24.5)$ & $19(20.2)$ & $18(31.6)$ \\
\hline Medium education level & $52(34.4)$ & $31(33.0)$ & $21(36.8)$ \\
\hline High education level & $62(41.1)$ & $44(46.8)$ & $18(31.6)$ \\
\hline Clinical characteristics & Mean (SD) & Mean (SD) & Mean (SD) \\
\hline Time since diagnosis (y) & $5.7(1.8)$ & $5.7(1.8)$ & $5.7(1.8)$ \\
\hline
\end{tabular}




\begin{tabular}{|llll|}
\hline & $\begin{array}{l}\text { Total } \\
(\mathbf{N = 1 5 5 )}\end{array}$ & $\begin{array}{l}\text { Men } \\
\mathbf{( N = 9 6 , 6 2 \% )}\end{array}$ & $\begin{array}{l}\text { Women } \\
\mathbf{( N = 5 9 , 3 8 \% )}\end{array}$ \\
\hline & $\mathbf{N}(\%)$ & $N(\%)$ & $N(\%)$ \\
\hline 1 comorbid condition & $38(24.7)$ & $24(25.0)$ & $14(24.1)$ \\
\hline $2+$ comorbid conditions & $79(51.3)$ & $47(49.0)$ & $32(55.2)$ \\
\hline Chemotherapy (yes) & $80(51.6)$ & $51(53.1)$ & $29(49.2)$ \\
\hline Radiotherapy (yes) & $60(38.7)$ & $45(46.9)$ & $15(25.4)$ \\
\hline Tumour localization (colon) & $83(53.5)$ & $41(42.7)$ & $42(71.2)$ \\
\hline Tumour stage I & $43(29.3)$ & $25(28.4)$ & $18(30.5)$ \\
\hline Tumour stage II & $54(36.7)$ & $32(36.4)$ & $22(37.3)$ \\
\hline Tumour stage III & $50(34.0)$ & $31(35.2)$ & $19(32.2)$ \\
\hline
\end{tabular}

\section{Anthropometric measures}

As shown in Table 1, mean BMI (27.5 vs. $28.1 \mathrm{~kg} / \mathrm{m} 2)$ and body fat percentage (31.6\% vs. 40.5\%) among men was lower compared to women. Men had a larger waist circumference (102.3 vs. $96.7 \mathrm{~cm}$ ) and a higher waist-tohip ratio (1.02 vs. 0.91) compared to women. Also, maximum HGS (44.1 vs. $25.7 \mathrm{~kg}$ ) and mid-upper arm muscle area (511.4 vs. $401.7 \mathrm{~cm}^{2}$ ) were higher for men compared to women.

\section{HRQoL Outcomes}

The mean scores for global quality of life, physical functioning, role functioning, social functioning, fatigue and disability in the study population were 77.8 (SD = 18.1), 80.5 (SD = 20.6), 83.1 (SD = 25.2), 89.0 (SD = 18.9), 56.7 $(S D=26.9)$ and $12.4(S D=15.4)$ respectively, as shown in Table 2. 
Table 2

Results of linear regression analyses of associations of body composition parameters with health-related quality of life (HRQoL) outcomes.

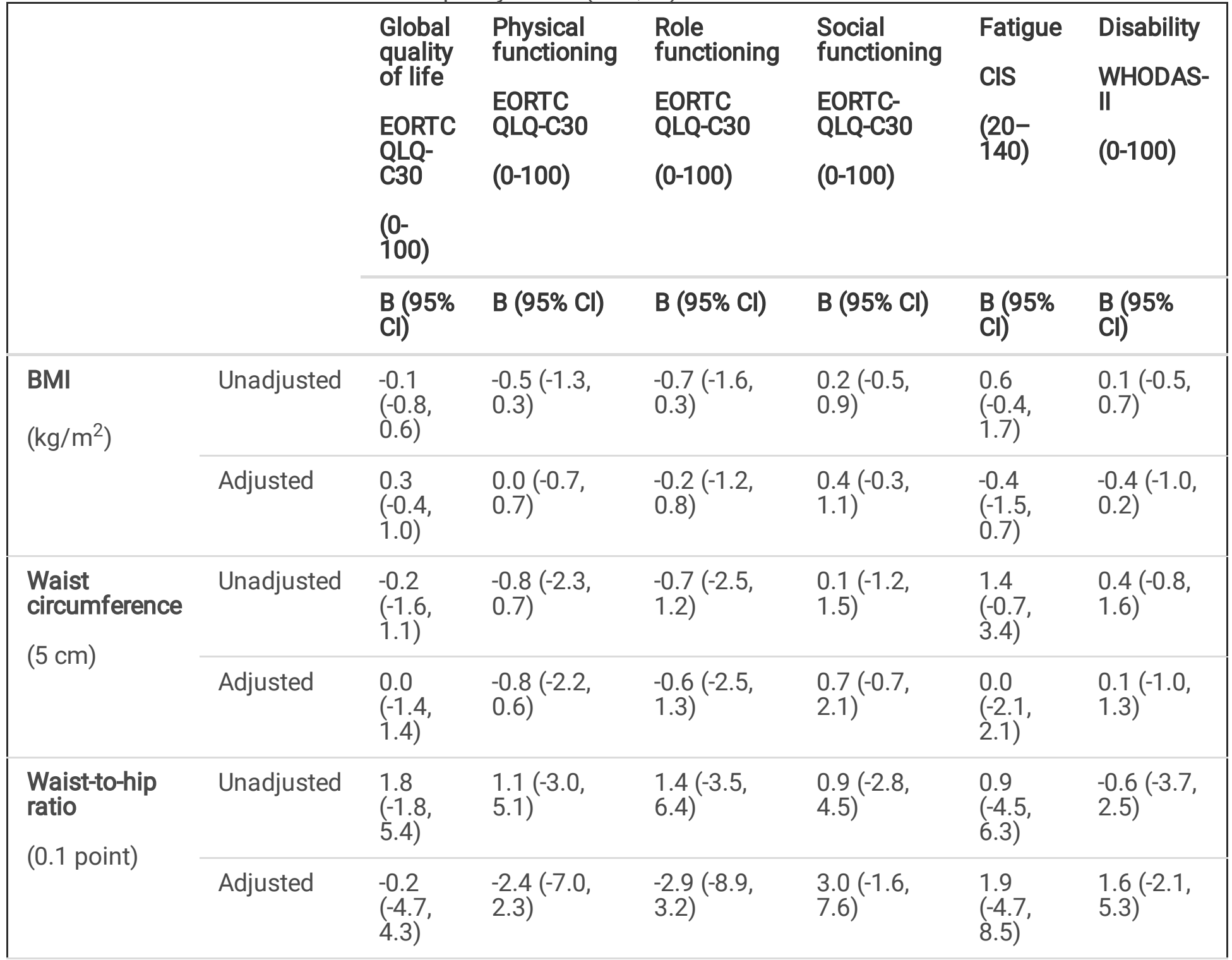

Regression coefficients reflect the change in the HRQoL outcomes per unit change in the body composition parameters. To facilitate interpretation, the units of the body composition parameters (except for BMI) were adapted for inclusion in the regression models, i.e., waist circumference in units of $5 \mathrm{~cm}$, waist-to-hip ratio in units of 0.1 points, body fat in units of $5 \%, \mathrm{HGS}$ in units of $5 \mathrm{~kg}$ and mid-upper arm muscle area in units of $10 \mathrm{~cm}^{2}$.

Adjusted for age $(\mathrm{y})$, gender, time since colorectal cancer diagnosis $(\mathrm{y})$, comorbidities $(0 / 1 / 2+$ self-reported comorbid conditions), chemotherapy treatment (yes/no), current smoking (yes/no), moderate-to-vigorous physical activity $(\mathrm{h} / \mathrm{w})$, sedentary time accumulated in prolonged bouts of $30+\mathrm{min}(\mathrm{h} / \mathrm{d})$, total energy intake $(\mathrm{kcal} / \mathrm{d})$, education level (low/medium/high).

*: $P<0.05 ;{ }^{* \star}: P<0.01 ;{ }^{* \star}: P<0.001$

Abbreviations: EORTC QLQ-C30: European Organisation for Research and Treatment of Cancer Quality of Life Questionnaire-Core 30; CIS: Checklist Individual Strength; WHODAS-II: World Health Organization Disability Assessment Schedule II; BMI: Body Mass Index. 


\begin{tabular}{|c|c|c|c|c|c|c|c|}
\hline & & $\begin{array}{l}\text { Global } \\
\text { quality } \\
\text { of life }\end{array}$ & $\begin{array}{l}\text { Physical } \\
\text { functioning }\end{array}$ & $\begin{array}{l}\text { Role } \\
\text { functioning }\end{array}$ & $\begin{array}{l}\text { Social } \\
\text { functioning }\end{array}$ & $\begin{array}{l}\text { Fatigue } \\
\text { CIS }\end{array}$ & $\begin{array}{l}\text { Disability } \\
\text { WHODAS- }\end{array}$ \\
\hline & & EORTC & QLQ-C30 & QLQ-C30 & QLQ-C30 & $(20-$ & 11 \\
\hline & & C30 & $(0-100)$ & $(0-100)$ & $(0-100)$ & & \\
\hline & & $\begin{array}{l}(0- \\
100)\end{array}$ & & & & & \\
\hline & & $\begin{array}{l}\mathrm{B}(95 \% \\
\mathrm{Cl})\end{array}$ & B $(95 \% \mathrm{Cl})$ & B $(95 \% \mathrm{Cl})$ & B $(95 \% \mathrm{Cl})$ & $\begin{array}{l}\mathrm{B}(95 \% \\
\mathrm{Cl})\end{array}$ & $\begin{array}{l}\mathrm{B}(95 \% \\
\mathrm{Cl})\end{array}$ \\
\hline $\begin{array}{l}\text { Body fat } \\
(5 \%)\end{array}$ & Unadjusted & $\begin{array}{l}-2.4 \\
(-4.8 \\
-0.1)^{*}\end{array}$ & $\begin{array}{l}-3.9(-6.5 \\
-1.3)^{\star \star}\end{array}$ & $\begin{array}{l}-5.0(-8.2 \\
-1.8)^{\star \star}\end{array}$ & $\begin{array}{l}0.0(-2.4 \\
2.4)\end{array}$ & $\begin{array}{l}3.7 \\
(0.2, \\
7.2)^{*}\end{array}$ & $\begin{array}{l}2.3(0.3 \\
4.3)^{\star}\end{array}$ \\
\hline & Adjusted & $\begin{array}{l}-0.8 \\
(-4.2 \\
2.5)\end{array}$ & $\begin{array}{l}-1.7(-5.1 \\
1.8)\end{array}$ & $\begin{array}{l}-3.4(-7.8 \\
1.0)\end{array}$ & $\begin{array}{l}-0.2(-3.6 \\
3.2)\end{array}$ & $\begin{array}{l}2.5 \\
(-2.4 \\
7.4)\end{array}$ & $\begin{array}{l}0.6(-2.1 \\
3.4)\end{array}$ \\
\hline $\begin{array}{l}\text { Maximum } \\
\text { handgrip } \\
\text { strength }\end{array}$ & Unadjusted & $\begin{array}{l}1.8 \\
(0.6 \\
3.0)^{\star *}\end{array}$ & $\begin{array}{l}3.2(1.9 \\
4.4)^{\star \star \star}\end{array}$ & $\begin{array}{l}2.8(1.2 \\
4.4)^{* \star}\end{array}$ & $\begin{array}{l}1.4(0.2, \\
2.6)^{\star}\end{array}$ & $\begin{array}{l}-2.7 \\
(-4.4 \\
-0.9)^{* *}\end{array}$ & $\begin{array}{l}-2.0(-3.0 \\
-0.9)^{\star \star \star}\end{array}$ \\
\hline$(5 \mathrm{~kg})$ & Adjusted & $\begin{array}{l}2.3 \\
(0.3 \\
4.3)^{*}\end{array}$ & $\begin{array}{l}2.9(0.9, \\
5.0)^{\star \star}\end{array}$ & $\begin{array}{l}2.6(-0.1 \\
5.3)\end{array}$ & $\begin{array}{l}3.3(1.3 \\
5.3)^{\star \star}\end{array}$ & $\begin{array}{l}-5.9 \\
(-8.7 \\
-3.0)^{* \star \star}\end{array}$ & $\begin{array}{l}-2.5(-4.1 \\
-0.9)^{\star \star}\end{array}$ \\
\hline $\begin{array}{l}\text { Mid-upper } \\
\text { arm muscle } \\
\text { area }\end{array}$ & Unadjusted & $\begin{array}{l}0.2 \\
(-0.0 \\
0.5)\end{array}$ & $\begin{array}{l}0.3(0.0 \\
0.6)^{\star}\end{array}$ & $\begin{array}{l}0.2(-0.1 \\
0.6)\end{array}$ & $\begin{array}{l}0.1(-0.2 \\
0.3)\end{array}$ & $\begin{array}{l}-0.4 \\
(-0.8 \\
0.0)\end{array}$ & $\begin{array}{l}-0.2(-0.5 \\
-0.0)^{\star}\end{array}$ \\
\hline$\left(10 \mathrm{~cm}^{2}\right)$ & Adjusted & $\begin{array}{l}0.2 \\
(-0.1 \\
0.5)\end{array}$ & $\begin{array}{l}0.1(-0.2 \\
0.4)\end{array}$ & $\begin{array}{l}0.0(-0.4 \\
0.4)\end{array}$ & $\begin{array}{l}0.1(-0.2 \\
0.4)\end{array}$ & $\begin{array}{l}-0.5 \\
(-0.9 \\
-0.1)^{\star}\end{array}$ & $\begin{array}{l}-0.2(-0.4 \\
0.1)\end{array}$ \\
\hline Mean score (S & & $\begin{array}{l}77.6 \\
(18.1)\end{array}$ & $80.5(20.6)$ & $83.1(25.2)$ & $89.0(18.9)$ & $\begin{array}{l}56.7 \\
(26.9)\end{array}$ & $\begin{array}{l}12.4 \\
(15.4)\end{array}$ \\
\hline $\begin{array}{l}\text { Regression co } \\
\text { parameters. Tc } \\
\text { adapted for in } \\
\text { units of } 0.1 \text { po } \\
10 \mathrm{~cm}^{2} \text {. }\end{array}$ & $\begin{array}{l}\text { Icients reflect } \\
\text { acilitate interp } \\
\text { usion in the res } \\
\text { ts, body fat in }\end{array}$ & $\begin{array}{l}\text { he change } \\
\text { etation, th } \\
\text { ression m } \\
\text { units of } 5 \%\end{array}$ & $\begin{array}{l}\text { in the HRQoL } \\
\text { e units of the } \\
\text { dels, i.e., wais } \\
\text {, HGS in units }\end{array}$ & $\begin{array}{l}\text { utcomes per } \\
\text { ody compositi } \\
\text { circumference } \\
\text { f } 5 \mathrm{~kg} \text { and mi }\end{array}$ & $\begin{array}{l}\text { it change in } \\
\text { n parameters } \\
\text { in units of } 5 \text { c } \\
\text {-upper arm } \mathrm{ml}\end{array}$ & $\begin{array}{l}\text {, waist-to } \\
\text { cle area it }\end{array}$ & $\begin{array}{l}\text { nposition } \\
\text { 3MI) were } \\
\text { hip ratio in } \\
\text { units of }\end{array}$ \\
\hline $\begin{array}{l}\text { Adjusted for a } \\
\text { comorbid conc } \\
\text { physical activi } \\
\text { (kcal/d), educa }\end{array}$ & $\begin{array}{l}\text { (y), gender, tir } \\
\text { ions), chemoth } \\
\text { (h/w), sedent } \\
\text { on level (low/r }\end{array}$ & $\begin{array}{l}\text { le since cc } \\
\text { erapy trea } \\
\text { ry time ac } \\
\text { edium/hi }\end{array}$ & $\begin{array}{l}\text { lorectal cance } \\
\text { tment (yes/no } \\
\text { cumulated in } \\
\text { h). }\end{array}$ & $\begin{array}{l}\text { diagnosis (y), } \\
\text { current smoki } \\
\text { olonged bouts }\end{array}$ & $\begin{array}{l}\text { omorbidities } \\
\text { of (yes/no), m } \\
\text { of } 30+\min (h\end{array}$ & $\begin{array}{l}/ 1 / 2+\text { sel } \\
\text { derate-to- } \\
\text { d), total en }\end{array}$ & $\begin{array}{l}\text {-reported } \\
\text { gorous } \\
\text { ergy intake }\end{array}$ \\
\hline *: $P<0.05{ }^{* *}: P$ & $0.01{ }^{* \star \star}: \mathrm{P}<0$. & & & & & & \\
\hline $\begin{array}{l}\text { Abbreviation } \\
\text { Life Questio } \\
\text { Disability As }\end{array}$ & $\begin{array}{l}\text { RTC QLQ-C3 } \\
\text {-Core 30; Cl } \\
\text { ent Schedu }\end{array}$ & $\begin{array}{l}\text { urope } \\
\text { hecklis }\end{array}$ & $\begin{array}{l}\text { Drganisatior } \\
\text { Idividual St } \\
\text { dy Mass Ind }\end{array}$ & $\begin{array}{l}\text { r Research } \\
\text { gth; WHODA }\end{array}$ & $\begin{array}{l}\text { Treatment } \\
\text { : World Hea }\end{array}$ & $\begin{array}{l}\text { Cancer } \\
\text { Organiz }\end{array}$ & $\begin{array}{l}\text { lity of } \\
\text { on }\end{array}$ \\
\hline
\end{tabular}

\section{Anthropometric variations in relation to HRQoL outcomes}


In unadjusted analyses (Table 2), no significant associations between BMI, waist circumference, waist-to-hip ratio and HRQoL outcomes were found. Nevertheless, each increase of $5 \%$ in body fat was significantly associated with a decrease in global quality of life score, physical functioning score, role functioning score, and an increase of fatigue symptoms and participants' disability score. After adjustment for patient and treatment characteristics, all associations between body fat and HRQoL outcomes were attenuated and no longer statistically significant.

Additionally, in unadjusted analyses, each increase in participants' HGS of $5 \mathrm{~kg}$ was significantly associated with an increase in global quality of life, physical functioning, role functioning, social functioning, and a decrease of fatigue symptoms and disability. After adjustment for patient and treatment characteristics, all associations, except for role functioning, remained statistically significant. After adjustment, each increase in participants' HGS of $5 \mathrm{~kg}$ was significantly associated with an increase of 2.3 points $(95 \% \mathrm{Cl}=0.3,4.3)$ in global quality of life, 2.9 points $(95 \% \mathrm{Cl}=0.9,5.0)$ in physical functioning, and 3.3 points $(95 \% \mathrm{Cl}=1.3,5.3)$ in social functioning, and a decrease of 5.9 points $(95 \% \mathrm{Cl}=-8.7,-3.0)$ in fatigue symptoms and 2.5 points $(95 \% \mathrm{Cl}=-4.1$, $-0.9)$ in disability.

Each $10 \mathrm{~cm}^{2}$ increase in mid-upper arm muscle area was significantly associated with an increase in physical functioning and a decrease in disability symptoms. After adjustment, these associations disappeared, but a decrease of 0.5 points $(95 \% \mathrm{Cl}=-0.9,-0.1)$ in fatigue with each $10 \mathrm{~cm}^{2}$ increase in mid-upper arm muscle area became statistically significant.

\section{Discussion}

In this cross-sectional study among 155 patients who underwent surgical treatment for stage I-III CRC, we found that a lower HGS was independently associated with poorer scores of almost all specific HRQoL domains 2 to 10 years after CRC treatment and that lower mid-upper arm muscle area was found to be independently associated with more fatigue symptoms. Although body fat and lower mid-upper arm muscle area were found to be associated with poorer scores in most HRQoL domains in unadjusted analyses, these associations attenuated after adjustment for differences in age, gender, years since diagnosis, comorbidities, chemotherapy treatment, current smoking, moderate-to-vigorous physical activity, sedentary time, and total energy intake. This indicates that the associations can be explained by confounding by the aforementioned factors.

A main finding was that lower HGS - as a measure of muscle mass and physical functioning - was independently associated with poorer HRQoL outcomes. Patients with a better HGS had a significantly higher score in global quality of life, physical functioning and social functioning. Moreover, a better HGS was associated with fewer complaints of fatigue and disability in patients after CRC treatment. As we adjusted for several relevant patient and treatment characteristics, these associations are probably not explained by confounding, that is, by the fact that CRC survivors with lower HGS are e.g. older, are more often female or smokers, have more comorbidities, received chemotherapy more often, have less moderate-to-vigorous physical activity and more sedentary time, and have a lower total energy intake. These cross-sectional results are in line with findings of a previous cross-sectional study that showed a significant association between lower HGS and lower global quality of life in frail elderly people after adjustment for age and sex [54]. Also, in prospective studies among patients with breast cancer and advanced small non-cell lung carcinoma, a lower HGS before 
treatment was related to lower HRQoL after treatment $[32,33]$. Similar prospective studies investigating a comparable direct association between HGS and patients' HRQoL in CRC survivors are lacking.

We found that lower HGS and lower mid-upper arm muscle area were independently associated with more fatigue symptoms, although effect sizes of lower mid-upper arm muscle area were small. Previous crosssectional studies found a similar association between lower muscle mass at time of diagnosis and the occurrence of cancer-related fatigue symptoms among advanced cancer patients $[55,56]$. Pathophysiology behind this could be found in pro-inflammatory effects of cancer-related cytokine changes which causes changes in activity of the hypothalamus-pituitary-adrenal axis, enhancing fatigue symptoms on the one hand and alter muscle metabolism leading to lower muscle mass on the other hand $[57,58]$. Both atrophy and loss of skeletal muscle fibers occurs mainly in type II, fast twitch glycolytic fibers, resulting in relatively higher density of remaining type I, slow twitch oxidative fibers with a supposed preservation of muscle endurance but a reduction in muscle strength [59]. As HGS is mainly a measure for muscle strength instead of muscle endurance, a reduced HGS can be expected in patients with a lower muscle mass.

Because of our cross-sectional design, it is hard to draw firm conclusions based on both our data and the current literature, as one may discuss the causality between body composition and physical functioning in CRC survivors. It can be hypothesized that cancer treatment-related effects alter body composition leading to a decrease in body strength which causes a loss of physical functioning. In addition, a loss of physical functioning as a result of cancer-related adverse effects may lead to an altered body composition and thereby loss of muscle strength [14]. The direction of a possible causal relation between body composition and physical functioning should be investigated in future longitudinal research. Moreover, a previous cross-sectional study of our research group found that a higher level of physical activity was associated with better HRQoL, physical function and wellbeing, and less CRC-specific symptoms after treatment $[9,60]$. This emphasizes the importance of optimizing and maintaining a good body composition by encouraging physical activity among CRC survivors. Multimodal and customized re- and pre-habilitation programs may be future solutions for the improvement of cancer patients' physical and psychological resistance on the unfavourable consequences of cancer and its treatment $[61,62]$.

Our study was strengthened by the use of validated measurements for collection of both anthropometric and HRQoL data, especially the standardized collection of several anthropometric measures. Notwithstanding, our study was limited by its cross-sectional design whereby the previously stated causality cannot be assumed and a possible association with pre-existing poor body measurements and a possible influence of cancer treatment is lacking. Another limitation of our study was the possibility of selection bias as survivors with an already unfavourable body composition or an already existing lower HRQoL may have been less likely to participate, which could have decreased the magnitude of the associations we observed. Although associations between anthropometric measures and HRQoL were adjusted for age, gender, years since diagnosis, comorbidities, chemotherapy treatment, current smoking, moderate-to-vigorous physical activity, sedentary time and total energy intake, residual confounding might play a role.

Results of this cross-sectional study have shown that HGS in CRC survivors, as a measure of physical functioning, is independently associated with several HRQoL outcomes. Future prospective research should investigate underlying and causal factors in the association between HGS and HRQoL after CRC treatment. These studies are necessary to investigate whether certain anthropometric measurements are prognostic factors 
for better outcome in terms of physical functioning and HRQoL in CRC survivors and to investigate which interventions can be applied to improve anthropometric measures in CRC survivors with better physical functioning and HRQoL as a result.

\section{Declarations}

Funding: Fund for cooperation VieCuri Medical Centre and Maastricht University Medical Centre. The crosssectional part of the EnCoRe study was funded by grants from the Stichting Alpe d'HuZes within the research program 'Leven met kanker' of the Dutch Cancer Society (Grant No. UM-2010-4867 and UM-2012-5653) and by Kankeronderzoekfonds Limburg as part of Health Foundation Limburg (Grant No. 00005739).

Conflicts of interest/Competing interests: The authors declare that they have no conflict of interest.

Availability of data and material: The authors have full control of all primary data and agree to allow the journal to review it if requested.

Code availability: N/A

Authors' contributions: M.W., N.B. and M.B. contributed to the data collection. M.H., M.W., M.J. and M.B. performed the statistical analysis. M.H. wrote the paper. J.K., M.B., N.B., M.W. and M.J. helped editing the paper. All authors were involved in critical revision and approval of the final version.

Ethics approval: The EnCoRe study had been approved by the Medical Ethics Committee of the Academic Hospital Maastricht and Maastricht University, the Netherlands.

Consent to participate: Written informed consent was obtained from all participants.

Consent for publication: Written informed consent was obtained from all participants.

\section{Acknowledgements:}

The authors would like to thank the EnCoRe study participants, the EnCoRe study research team (P. van der A Wesselink, N. Wijckmans, D.O. Klein, Y.L.L. Vanlingen, C.M.J. Gielen, and A.G.E. Smeets), the registration teams of the Comprehensive Cancer Centre Netherlands and Comprehensive Cancer Centre South for the collection of data for the Netherlands Cancer Registry and the scientific staff of the Comprehensive Cancer Centre.

\section{References}

1. Favoriti, P., et al., Worldwide burden of colorectal cancer: a review. Updates Surg, 2016. 68(1): p. 7-11.

2. Valle, I., D. Tramalloni, and N.L. Bragazzi, Cancer prevention: state of the art and future prospects. J Prev Med Hyg, 2015. 56(1): p. E21-7.

3. Rabeneck, L., et al., Colorectal Cancer, in Cancer: Disease Control Priorities, Third Edition (Volume 3), H. Gelband, et al., Editors. 2015, The International Bank for Reconstruction and Development / The World Bank . 
4. Torre, L.A., et al., Global Cancer Incidence and Mortality Rates and Trends--An Update. Cancer Epidemiol Biomarkers Prev, 2016. 25(1): p. 16-27.

5. Brigic, A., et al., A prospective case control study of functional outcomes and related quality of life after colectomy for neoplasia. Int J Colorectal Dis, 2017. 32(6): p. 777-787.

6. Vallance, J.K., et al., Associations of objectively assessed physical activity and sedentary time with healthrelated quality of life among colon cancer survivors. Cancer, 2014. 120(18): p. 2919-26.

7. Rodriguez, J.L., et al., Factors Associated with Health-Related Quality of Life Among Colorectal Cancer Survivors. Am J Prev Med, 2015. 49(6 Suppl 5): p. S518-27.

8. Lynch, B.M., et al., Erratum to: Patterns and correlates of accelerometer-assessed physical activity and sedentary time among colon cancer survivors. Cancer Causes Control, 2016. 27(7): p. 953.

9. Van Roekel, E.H., et al., Light Physical Activity Is Associated with Quality of Life after Colorectal Cancer. Med Sci Sports Exerc, 2015. 47(12): p. 2493-503.

10. Lynch, B.M., E.H. van Roekel, and J.K. Vallance, Physical activity and quality of life after colorectal cancer: overview of evidence and future directions. Expert Review of Quality of Life in Cancer Care, 2016. 1(1): p. 9-23.

11. Blanchard, C.M., K.S. Courneya, and K. Stein, Cancer survivors' adherence to lifestyle behavior recommendations and associations with health-related quality of life: results from the American Cancer Society's SCS-II. J Clin Oncol, 2008. 26(13): p. 2198-204.

12. Williams, J.P., et al., Effect of tumor burden and subsequent surgical resection on skeletal muscle mass and protein turnover in colorectal cancer patients. Am J Clin Nutr, 2012. 96(5): p. 1064-70.

13. De Backer, I.C., et al., High-intensity strength training improves quality of life in cancer survivors. Acta Oncol, 2007. 46(8): p. 1143-51.

14. Hanson, E.D., et al., The Independent Effects of Strength Training in Cancer Survivors: a Systematic Review. Curr Oncol Rep, 2016. 18(5): p. 31.

15. CL, B., et al., Complementary therapies in the management of cancer treatment-related symptoms: the individualized prescriptive exercise intervention approach. . Med Sport, 2006. 10(2): p. 49-57.

16. Lucia, A., C. Earnest, and M. Perez, Cancer-related fatigue: can exercise physiology assist oncologists? Lancet Oncol, 2003. 4(10): p. 616-25.

17. Bianchini, F., R. Kaaks, and H. Vainio, Overweight, obesity, and cancer risk. Lancet Oncol, 2002. 3(9): p. 56574.

18. Cohen, S., J.A. Nathan, and A.L. Goldberg, Muscle wasting in disease: molecular mechanisms and promising therapies. Nat Rev Drug Discov, 2015. 14(1): p. 58-74.

19. Steginga, S.K., et al., Antecedents of domain-specific quality of life after colorectal cancer. Psychooncology, 2009. 18(2): p. 216-20. 
20. Trentham-Dietz, A., et al., Health-related quality of life in female long-term colorectal cancer survivors. Oncologist, 2003. 8(4): p. 342-9.

21. Schlesinger, S., et al., Lifestyle factors and health-related quality of life in colorectal cancer survivors. Cancer Causes Control, 2014. 25(1): p. 99-110.

22. Vissers, P.A.J., et al., The Impact of Body Mass Index and Waist Circumference on Health-related Quality of Life Among Colorectal Cancer Survivors: Results from the PROFILES Registry. Nutr Cancer, 2017. 69(8): p. 11771184.

23. van Roekel, E.H., et al., Associations of adipose and muscle tissue parameters at colorectal cancer diagnosis with long-term health-related quality of life. Qual Life Res, 2017. 26(7): p. 1745-1759.

24. Adams, S.V., R. Ceballos, and P.A. Newcomb, Quality of Life and Mortality of Long-Term Colorectal Cancer Survivors in the Seattle Colorectal Cancer Family Registry. PLoS One, 2016. 11(6): p. e0156534.

25. Buffart, L.M., et al., Self-reported physical activity: its correlates and relationship with health-related quality of life in a large cohort of colorectal cancer survivors. PLoS One, 2012. 7(5): p. e36164.

26. Kilgour, R.D., et al., Handgrip strength predicts survival and is associated with markers of clinical and functional outcomes in advanced cancer patients. Support Care Cancer, 2013. 21(12): p. 3261-70.

27. Prizment, A.E., et al., Survival of women with colon cancer in relation to precancer anthropometric characteristics: the lowa Women's Health Study. Cancer Epidemiol Biomarkers Prev, 2010. 19(9): p. $2229-37$.

28. Riedl, A., et al., Comparison of different measures of obesity in their association with health-related quality of life in older adults - results from the KORA-Age study. Public Health Nutr, 2016. 19(18): p. 3276-3286.

29. Jimenez-Monreal, A.M., et al., Anthropometric and Quality-of-Life Parameters in Acute Intermittent Porphyria Patients. Medicine (Baltimore), 2015. 94(30): p. e1023.

30. O'Gorman, P., D.C. McMillan, and C.S. McArdle, Impact of weight loss, appetite, and the inflammatory response on quality of life in gastrointestinal cancer patients. Nutr Cancer, 1998. 32(2): p. 76-80.

31. Haider, S., et al., Associations between daily physical activity, handgrip strength, muscle mass, physical performance and quality of life in prefrail and frail community-dwelling older adults. Qual Life Res, 2016. 25(12): p. 3129-3138.

32. Takayama, K., et al., Quality of life and survival survey of cancer cachexia in advanced non-small cell lung cancer patients-Japan nutrition and QOL survey in patients with advanced non-small cell lung cancer study. Support Care Cancer, 2016. 24(8): p. 3473-80.

33. Ariza-Garcia, A., et al., Influence of physical inactivity in psychophysiological state of breast cancer survivors. Eur J Cancer Care (Engl), 2013. 22(6): p. 738-45.

34. Jansen, L., et al., Quality of life among long-term (>/=5 years) colorectal cancer survivors--systematic review. Eur J Cancer, 2010. 46(16): p. 2879-88. 
35. van Roekel, E.H., et al., The applicability of the international classification of functioning, disability, and health to study lifestyle and quality of life of colorectal cancer survivors. Cancer Epidemiol Biomarkers Prev, 2014. 23(7): p. 1394-405.

36. Durnin, J.V. and J. Womersley, The relationship between skinfold thickness and body fat in adults of middle age. J Physiol, 1969. 200(2): p. 105p-106p.

37. Frisancho, A.R., New norms of upper limb fat and muscle areas for assessment of nutritional status. Am J Clin Nutr, 1981. 34(11): p. 2540-5.

38. Durnin, J.V. and J. Womersley, Body fat assessed from total body density and its estimation from skinfold thickness: measurements on 481 men and women aged from 16 to 72 years. Br J Nutr, 1974. 32(1): p. 77-97.

39. Mathiowetz, V., Comparison of Rolyan and Jamar dynamometers for measuring grip strength. Occup Ther Int, 2002. 9(3): p. 201-9.

40. Wang, A.Y., et al., Evaluation of handgrip strength as a nutritional marker and prognostic indicator in peritoneal dialysis patients. Am J Clin Nutr, 2005. 81(1): p. 79-86.

41. Aaronson, N.K., et al., The European Organization for Research and Treatment of Cancer QLQ-C30: a qualityof-life instrument for use in international clinical trials in oncology. J Natl Cancer Inst, 1993. 85(5): p. 365-76.

42. Bjordal, K., et al., A 12 country field study of the EORTC QLQ-C30 (version 3.0) and the head and neck cancer specific module (EORTC QLQ-H\&N35) in head and neck patients. EORTC Quality of Life Group. Eur J Cancer, 2000. 36(14): p. 1796-807.

43. Fayers, P. and A. Bottomley, Quality of life research within the EORTC\&\#x2014,the EORTC QLQ-C30. European Journal of Cancer. 38: p. 125-133.

44. Van der Hoeken, D., K. Riet-van Hoof, and H. Hoek, Dutch WHO-DAS II: questionnaire to assess disability. Den Haag, the Netherlands: WHO Collaborating Centre WHO-DAS, 2000.

45. Üstün, T.B., Measuring health and disability: Manual for WHO disability assessment schedule WHODAS 2.0. 2010: World Health Organization.

46. Tazaki, M., et al., Measuring functional health among the elderly: development of the Japanese version of the World Health Organization Disability Assessment Schedule II. Int J Rehabil Res, 2014. 37(1): p. 48-53.

47. Posl, M., A. Cieza, and G. Stucki, Psychometric properties of the WHODASII in rehabilitation patients. Qual Life Res, 2007. 16(9): p. 1521-31.

48. Vercoulen, J.H., et al., The measurement of fatigue in patients with multiple sclerosis. A multidimensional comparison with patients with chronic fatigue syndrome and healthy subjects. Arch Neurol, 1996. 53(7): p. 6429.

49. Vercoulen, J.H., et al., Dimensional assessment of chronic fatigue syndrome. J Psychosom Res, 1994. 38(5): p. 383-92. 
50. Servaes, P., et al., Fatigue in disease-free cancer patients compared with fatigue in patients with chronic fatigue syndrome. Support Care Cancer, 2001. 9(1): p. 11-7.

51. Wendel-Vos, G.C., et al., Reproducibility and relative validity of the short questionnaire to assess healthenhancing physical activity. J Clin Epidemiol, 2003. 56(12): p. 1163-9.

52. Annegarn, J., et al., Objective physical activity assessment in patients with chronic organ failure: a validation study of a new single-unit activity monitor. Arch Phys Med Rehabil, 2011. 92(11): p. 1852-1857.e1.

53. Sangha, O., et al., The Self-Administered Comorbidity Questionnaire: a new method to assess comorbidity for clinical and health services research. Arthritis Rheum, 2003. 49(2): p. 156-63.

54. Haider, S., et al., Associations between daily physical activity, handgrip strength, muscle mass, physical performance and quality of life in prefrail and frail community-dwelling older adults. Qual Life Res, 2016.

55. Neefjes, E.C.W., et al., Muscle mass as a target to reduce fatigue in patients with advanced cancer. J Cachexia Sarcopenia Muscle, 2017. 8(4): p. 623-629.

56. Kilgour, R.D., et al., Cancer-related fatigue: the impact of skeletal muscle mass and strength in patients with advanced cancer. J Cachexia Sarcopenia Muscle, 2010. 1(2): p. 177-185.

57. Ryan, J.L., et al., Mechanisms of cancer-related fatigue. Oncologist, 2007. 12 Suppl 1: p. 22-34.

58. Shafqat, A., et al., Screening studies for fatigue and laboratory correlates in cancer patients undergoing treatment. Ann Oncol, 2005. 16(9): p. 1545-50.

59. Boirie, Y., Physiopathological mechanism of sarcopenia. J Nutr Health Aging, 2009. 13(8): p. 717-23.

60. van Roekel, E.H., et al., Longitudinal associations of light-intensity physical activity with quality of life, functioning and fatigue after colorectal cancer. Qual Life Res, 2020. 29(11): p. 2987-2998.

61. Driessen, E.J., et al., Effects of prehabilitation and rehabilitation including a home-based component on physical fitness, adherence, treatment tolerance, and recovery in patients with non-small cell lung cancer: $A$ systematic review. Crit Rev Oncol Hematol, 2017. 114: p. 63-76.

62. Thomas, G., et al., A systematic review of randomised controlled trials investigating prehabilitation before major intra-abdominal cancer surgery: An analysis of prehabilitation content and outcome measures. Eur $\mathrm{J}$ Anaesthesiol, 2019.

\section{Figures}


Men and women ( $\geq 18$ years), with a history of stage I, II, or III colorectal cancer, including recurrent colorectal cancer treated at Maastricht University Medical Center+ between 2002-2010

( $n=772$ )

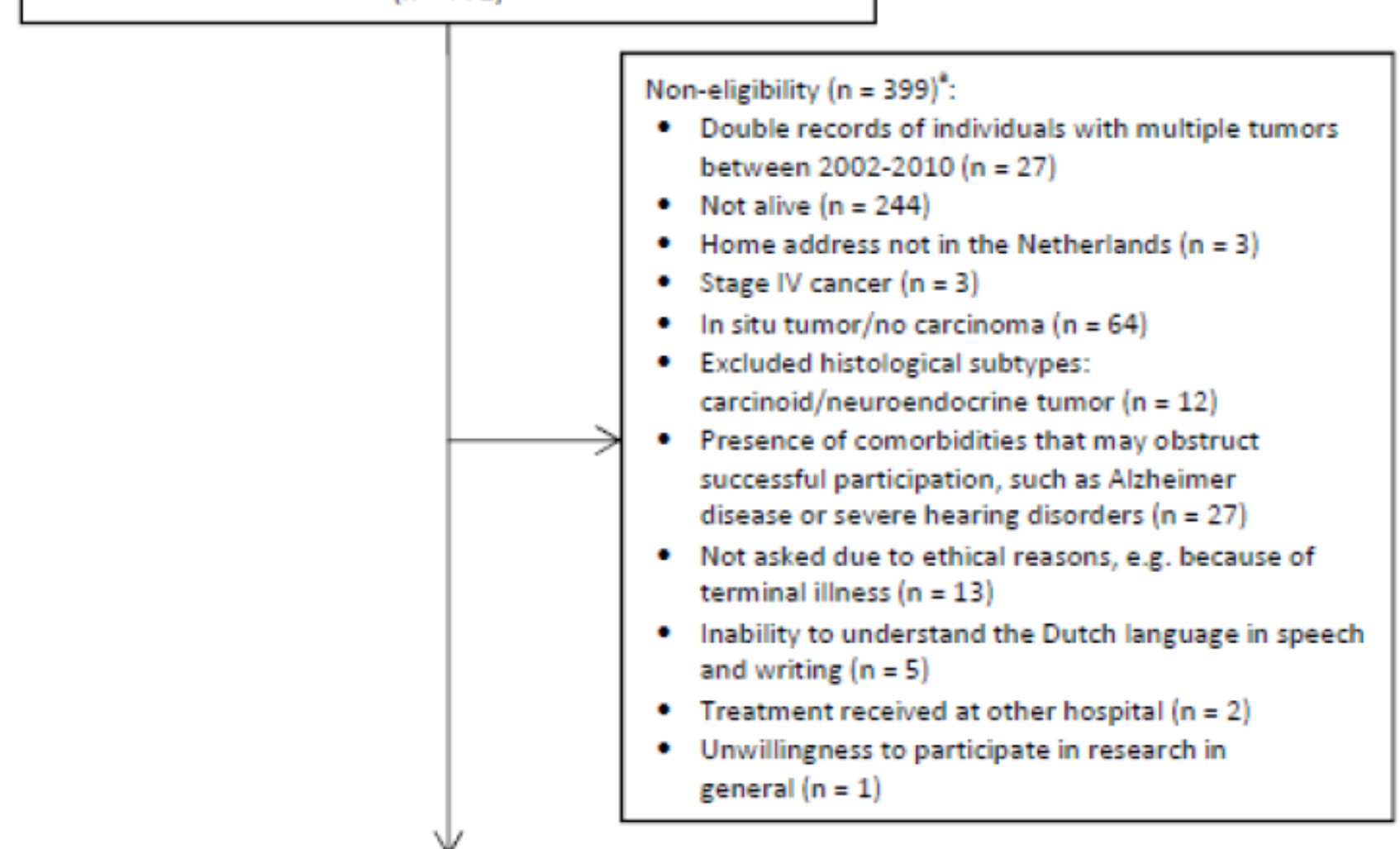

Eligible individuals were invited to participate by mail $(n=373)$

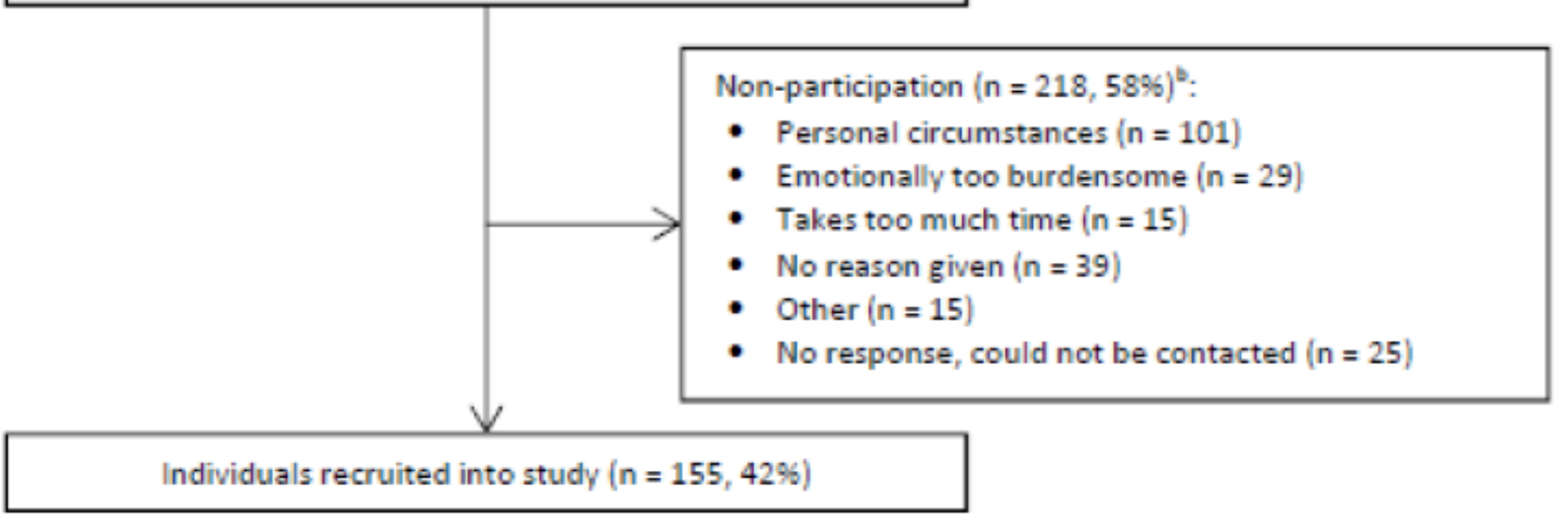

\section{Figure 1}

Flow diagram of inclusion of individuals into the cross-sectional part of the EnCoRe study and analyses presented in this paper. 